\title{
Relationship between Population Fluctuation of Oriental Fruit Fly Bactrocera dorsalis Hendel and Abiotic Factors in Yezin, Myanmar
}

\author{
N. N. Yin, Y. Y. Theint, K. M. Myaing, S. S. Oo, O. Khin, M. Yin, M. T. Aye, H. H. Hlaing, K. Swe and Naing \\ Kyi Win \\ Department of Agricultural Research (DAR), Yezin, Nay Pyi Taw 15013, Myanmar
}

\begin{abstract}
Population fluctuation of oriental fruit fly, Bactrocera dorsalis (Hendel) (Diptera: Tephritidae), was monitored by using methyl eugenol traps during May, 2011 to December, 2011 and May, 2016 to December, 2016 in mango orchard farms of Department of Agricultural Research in Yezin, Myanmar. In 2011, the highest mean number of male oriental fruit flies/trap/day $(241.42 \pm 11.79)$ was recorded in June and the lowest $(2.21 \pm 0.40)$ in December. The highest mean number of male oriental fruit flies/trap/day $(388.95 \pm 8.56)$ was recorded in the month of June and the lowest $(2.33 \pm 0.20)$ in December, 2016. Population data were correlated with meteorological data including temperature, duration of sunshine, and rainfall. Population fluctuation of male fruit flies was positively correlated with temperature and rainfall, and negatively correlated with the duration of sunshine.
\end{abstract}

Key words: Oriental fruit fly, Bactrocera dorsalis, population fluctuation, mango orchard.

\section{Introduction}

Fruit flies are major pests of mangoes in most parts of the world including temperate, subtropical and tropical countries [1]. Fruit flies infestation is a major constraint to fruit industry [2]. Fruit fly has been listed as an important quarantine in most countries for a wide host range, high fecundity and severe damage it causes to agricultural products [3]. Among them oriental fruit fly Bactrocera dorsalis is a widespread major pest of mango in the world [4]. It causes tremendous economic losses and great problems to the fruit and vegetable growers all over the world [5]. Oriental fruit fly is a serious pest of a wide variety of fruits and vegetables throughout its range and damage levels can be anything up to $100 \%$ of unprotected fruit [6].

In tropical Asia, Bactrocera dorsalis has been thought responsible for causing major economic losses to horticultural crops. It is now known that a

Corresponding author: Nwe Nwe Yin, director, research field: entomology. complex of at least 52 sibling species exist in the region, 40 of which are newly described species, and 8 of which are of economic importance [7]. In Myanmar, oriental fruit fly is a very wide spread and important pest of mango, citrus, guava and cashew [8]. Bactrocera dorsalis species complex can be found in Myanmar as an economic pest [7]. The abundance of larval hosts is one of the major factors regulating fruit fly populations [9].

Climate, particularly temperature and rainfall, is the main factor influencing the distribution of the fly. Local infestation patterns of Bactrocera dorsalis reportedly reflect local temperatures [10]. Bactrocera dorsalis completes more than five generations per year in most tropical regions, and as many as ten generations per year in particular tropical areas, but less than four generations per year in most subtropical regions [11]. Many conventional and advanced techniques of pest control have been tested to avoid the losses caused by fruit flies in the world [12]. Most of the efforts in fruit fly control and eradication have emphasized on mature adults include orchard 
sanitation, physical and chemical control by using bait traps [13], utilizing methyl eugenol [14], biological control and male sterile insect technique [15]. Detection of oriental fruit fly can be monitored by using traps which are baited with male lures. Methyl eugenol ( $O$-methyl eugenol) attracts at very low concentrations and it is found to lure over a range of up to $1 \mathrm{~km}$ [16]. It is very difficult to control the pest simply through the application of chemical pesticides due to their peculiar biological features. The objectives of this study were to monitor the population fluctuation patterns of Bactrocera dorsalis, and to determine the major factors affecting the population incidence in Yezin area.

\section{Materials and Methods}

\subsection{Study Area}

Field surveys of Bactrocera dorsalis adult population were carried out at six mango orchards in 2011 and 2016 in Department of Agricultural Research compound $\left(19^{\circ} 51^{\prime} \mathrm{N}\right.$ and $\left.96^{\circ} 07^{\prime} \mathrm{E}\right)$ in Yezin. Each of the mango orchards was approximately 1 ha in area. In these orchards, no pest control measures, including pesticide treatment, were performed during the study period. Different varieties of mangoes are representative of the major fruit cultivated in Yezin area, and also the plants that are commonly infested by oriental fruit fly.

\subsection{Study Methods}

Traps were handmade and constructed based on steiner trap. Three steiner traps, more than $50 \mathrm{~m}$ apart, were placed on fruit trees at a height of $2 \mathrm{~m}$ above the ground at each site. A pheromone lure was suspended inside each trap near the center. The lure consisted of a small cotton ball soaked with $2 \mathrm{~mL}$ of methyl eugenol, which was replaced at one week interval throughout the year. Male flies were attracted by the lures when they touched the cotton ball. Bactrocera dorsalis in each trap were identified and counted at one week interval starting from May, 2011 to
December, 2011 and May, 2016 to December, 2016. The number of Bactrocera dorsalis males caught is the average value per trap of all traps in each of the six mango orchards. The meteorological data such as temperature (maximum and minimum), rainfall and duration of sunshine were recorded from Yezin meteorological station in Department of Agricultural Research.

\subsection{Data Analysis}

The index of fruit fly population captured in traps was calculated based on the following formula:

F.T.D $($ flies/trap/day $)=F /(T \times D)$ where,

$\mathrm{F}=$ Total no. of flies;

$\mathrm{T}=$ No. of serviced traps;

$\mathrm{D}=$ Average no. of days traps were exposed (IAEA 2005) [17].

Data were statistically analyzed by using the Statistix 8.0 software programme. Correlation analysis was used to calculate between adult capture and three climatic factors: temperature, rainfall, and sunshine hours by the procedures outlined by Gomez et al. [18].

\section{Results and Discussion}

\subsection{Population Fluctuation of Oriental Fruit Fly}

Monthly mean number captures of Bactrocera dorsalis adult males fly per trap per day for each of the two study years in 2011 and 2016 were shown in Fig. 1. The seasonal fluctuation pattern for this fly population was mostly consistent for each of the study year. The highest mean numbers (273.75 flies/trap/day) (FTD) was found in June, 2011 and the lowest (5.98 FTD) was recorded in December, 2011. In 2016, the highest mean numbers (269.69 FTD) was found in June and the lowest (10.72 FTD) was recorded in December (Fig. 1). Two peak catches (273.75 and 269.69 FTD) were observed in June, 2011 of both years. Fruit fly infestations thus seem to be fruiting season in Yezin area. In the month of May, most of the Sein Ta Lone varieties were matured and 
temperature and humidity favorable so the fly population was increased. In the month of June and July, most of the mangoes were matured and ready to harvest and the maximum number of fruit flies was trapped. Shukla et al. [19] observed that the emergence of fruit fly starts from April onwards and the maximum population was recorded during May-July which coincides with fruit maturity. The finding of present investigation is in agreement with the results of Agarwal et al. [20] who reported that the maximum populations of peach fruit fly Bactrocera zonata, which was recorded during the third week of June (357 flies/trap) in India. The mean incidence obtained from two consecutive years of study also revealed the same trend. The seasonal fluctuation pattern for this fly population trapped by using methyl eugenol was mostly consistent for each of the study year. It was noted that host availability is one of the major factors of population fluctuation of fruit flies. These maximum catches coincided with ripening of mango fruits. Results obtained from this study agreed with the findings of Mwatawala et. al. [21] who mentioned that mango orchards present high numbers of flies during their fruiting season.

\subsection{Relationship between Abiotic Factors and Fruit Flies Population}

The population fluctuation of oriental fruit fly in different seasons of the year 2011 and 2016 trapped by using methyl eugenol trap was shown in Figs. 2 and 3. The highest mean numbers $(241.42 \pm 11.79$ FTD) was recorded in June 10, 2011 and the lowest mean numbers $(2.21 \pm 0.40$ FTD $)$ in December 23, 2011 (Fig. 1). The higher populations (138.06 126.69 FTD) was observed from May to 1st week of July in 2011. The mean number of fruit flies/trap/day trapped with methyl eugenol varied with receiving rainfall during the fruiting season of mango in 2011 (Fig. 2). Three peak catches (176.51, 241.42 and 191.75 F/T/D) were observed on May 20, June 10 and June 17, 2011 respectively, in the fruiting season mango in this study. In 2016, the highest mean numbers $(388.95 \pm 8.56$ FTD) was recorded on 6th June and the lowest mean numbers $(2.33 \pm 0.20$ FTD $)$ was observed on 12th December. The higher populations (359.48 - 112.19 FTD) were observed from May to August in 2016. Four peak catches (359.48, 364.52, 388.95 and 317.48 FTD) were recorded on May 23, May 30, Jun 6 and Jun 13, 2016, respectively. The incidence of fruit flies was recorded through the fruiting season of mango. Mwatawala et al. [21] reported that mango orchards present high numbers of flies during their fruiting season.

At the beginning of the fruiting season no rain was obtained at that period. After that it noticeably increased and reached the highest peak (241.42 FTD) by the first heavy rain $(15 \mathrm{~mm})$ on 10th June 2011. Then it was noted that the population was started increasing again and obtained high number of fruit flies (241.42 FTD) on 10th June 2011, (191.75 FTD) on 17th June, (141.33 FTD) on 24th June 2011 by receiving higher amount of rainfall of $15 \mathrm{~mm}$ and $23 \mathrm{~mm}$, respectively. On June 17, 2011, the mean number of fruit flies per trap per day was the second highest (191.75 FTD) when it was coincided with the heavy rain $(15 \mathrm{~mm})$ was shown in Fig. 2. Thereafter the population declined (141.33 and 126.69 FTD) when the amount of rainfall $23 \mathrm{~mm}$ was received on June 17, 2011. The incidence of fruit flies was observed throughout the study period. The highest peak (388.95 FTD) was recorded on $6^{\text {th }}$ June, 2016 by the first heavy rain (19 $\mathrm{mm}$ ) on $13^{\text {th }}$ June was shown in Fig. 3. In 2016, at the beginning of study, the population was very low and no rainfall was obtained at those periods. After that it noticeably increased and reached four peak catches (359.48, 364.52, 388.95 and 317.48 FTD) by the heavy rain $(33 \mathrm{~mm})$ on $3^{\text {rd }}$ June 2016 . The rain started from May up to October in 2016. Therefore, male oriental fruit flies fluctuated from May to October. It was noted that rainfall has a strong influence on incidence of fruit flies (Figs. 2 and 3). The population was gradually decreased from September to December. 

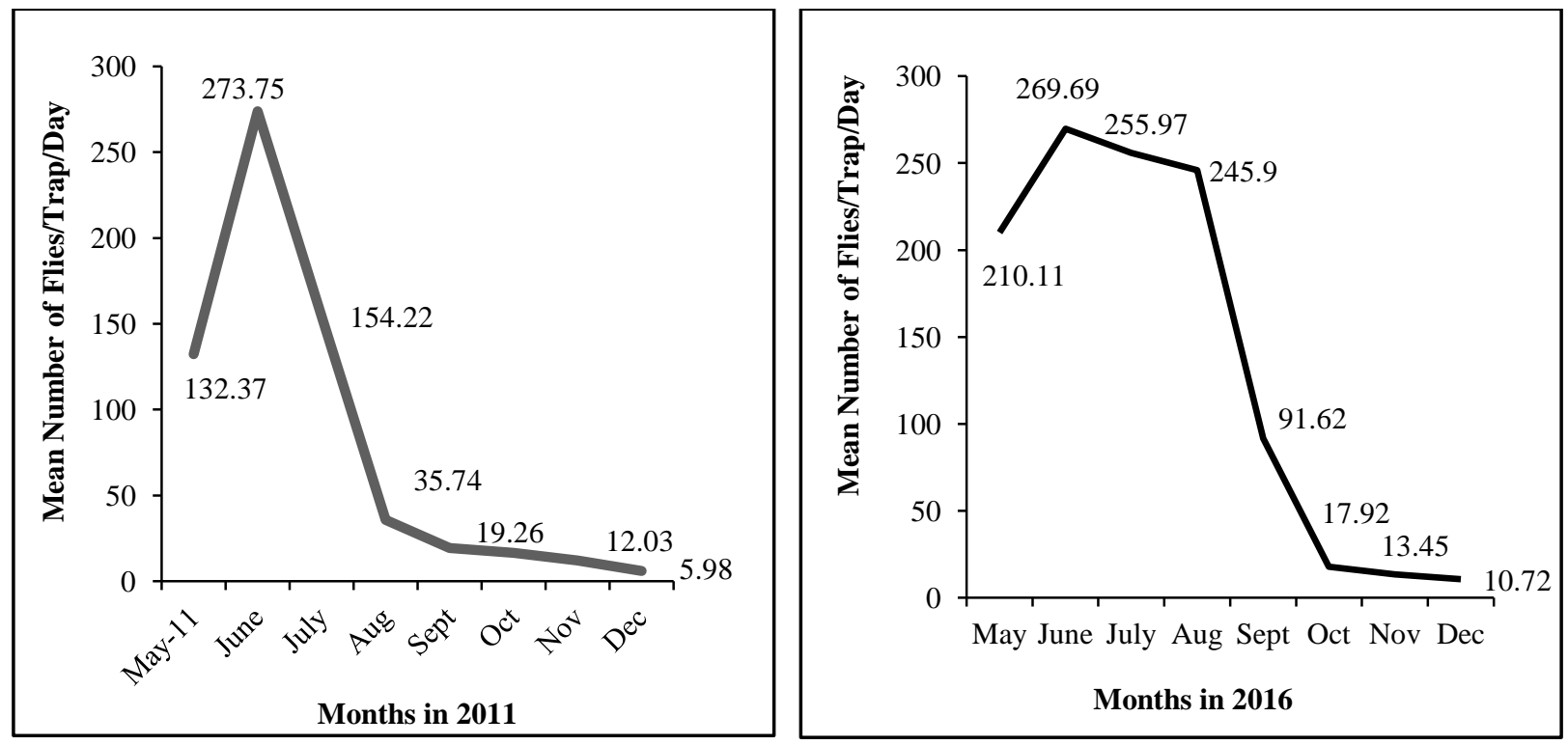

Fig. 1 Mean number of adult male fly Bactrocera dorsalis captured per trap per day in 2011 and 2016.

Low captures from September to December indicated the small population size or reduction of adult activity during winter and off-season of mango fruiting season. The positive impact of rainfall on the fly incidence was in corroboration with the earlier findings of Mahmood et al. [22]. Amice and Sales [23] observed that the influence of abiotic factors such as temperature and rainfall is closely related with fly population dynamics. Khan et al. [24] also reported that the weather factors showed significant contribution towards population fluctuation and among them, rainfall appeared as the important factor for population fluctuation.

The mean numbers of fruit flies fluctuated with maximum and minimum temperature in the fruiting season of mango in 2011 and 2016 were presented in Figs. 2 and 3. In the early fruiting season, the mean numbers of flies were very low from May 6 to June 3 with high temperature (maximum $38^{\circ} \mathrm{C}$ and minimum $25^{\circ} \mathrm{C}$ ) was recorded at that period (Fig. 2). Fletcher [25] reported that the temperature range permitting development and reproduction of fruit fly is $15-34{ }^{\circ} \mathrm{C}$ and the optimum temperature range is $18-30^{\circ} \mathrm{C}$. When the temperature is greater than $34^{\circ} \mathrm{C}$ or less than $15^{\circ} \mathrm{C}$, a large number of adults and larvae die. On June 10,
2011 the first generation peak (241.42 FTD) was obtained and the maximum and minimum temperature $28{ }^{\circ} \mathrm{C}$ and $24.5^{\circ} \mathrm{C}$ were observed at that time. When the temperature increased to $31{ }^{\circ} \mathrm{C}$ and $34.5^{\circ} \mathrm{C}$, the population decreased to 191.75 and 97.75 FTD on June 17 and July 8. Fig. 3 showed that the first peak population (388.95 FTD) was obtained and the maximum and minimum temperature $35^{\circ} \mathrm{C}$ and $25^{\circ} \mathrm{C}$ were observed at that time. Chen et al. [26] reported that temperature should be regarded as one of the main factors limiting the activity of fruit fly. Mann [27] observed that low catches of Bactrocera dorsalis may be due to the effect of high temperature $\left(31.93^{\circ} \mathrm{C}\right)$ in June. Similar findings had been reported by Verghese and Sudhadevi [28] and Gupta et al. [29] who pointed out fruit fly population of Bactrocera spp. had positive correlation with minimum temperature and maximum temperature. This finding was similar result of Laskar et al. [30] who observed that the mean maximum, minimum temperature showed positive and significant correlation with the fruit fly catch per trap per day. Lui et al. [31] reported that positive and highly significant correlation of Dacus zonatus incidence with minimum and maximum temperature.

The mean numbers of fruit flies per methyl eugenol 
trap varied with daily mean sunshine hour in the fruiting season of mango in 2011 and 2016 (Figs. 2 and 3). The number of fruit flies per trap was very low (i.e., 138.06 to 156.55 FTD) on May 6 to Jun 3, 2011 and the maximum sunshine hours $(8.3 \mathrm{hr}$ and $10.1 \mathrm{hr})$ were recorded at that time. Moreover, on June 10, the highest population number (241.42 FTD) was recorded when daily means sunshine hour was zero hour was shown Fig. 2. The highest population of male flies (388.95 FTD) was observed on 6th June, 2016, when the amount of sunshine hour was 4.2 hours. These result pointed out that sunshine hour might be negative impact on population of fruit flies in the fruit season of mango and it can be suggested that cloudy might favor increases in population size of fruit fly. The negative and significant correlation $(\mathrm{Pr}=$ 0.001 ) was observed between the mean number of fruit fly and sunshine hour (Table 1). Chen et al. [26] and Jalaluddin et al. [32] reported that there was a significant negative correlation between monthly population fluctuation and monthly sunshine hours. The result of present study was agreed with the observation of Laskar et al. [30] who exhibited that total sunshine hour per day influence negatively on adult melon fly incidence. Shukla et al. [19] also reported that the peak trap catches of Bactrocera dorsalis had a negative correlation with average number of day light hours. Chen et al. [26] expressed that there was a significant negative correlation between monthly population fluctuation and monthly duration of sunshine. Murthy et al. [33] also stated that incidence of morning fly Gitona spp. was negatively correlated with the duration of sunshine. Their results are in agreement with record of Jalaluddin et al. [32] who stated that weekly mean the duration of sunshine had low negative correlation with the catch. The influence of abiotic factors (such as temperature, rainfall and sunshine hour) is closely related and significant contribution with population fluctuation of fruit flies. In the month of December to February a few fruit flies were captured in the trap.
This is because of low temperature and no host available in the surroundings. On the onset of rainy season the fly population started to increase and during heavy rainfall population also higher. The population declined slowly from August to September after that is non-existent up to March which is more or less similar to our findings. Similar observation with regard to influence of meteorological parameters on the incidence of oriental fruit fly was also claimed earlier by several workers [19, 29].

The population fluctuation of oriental fruit fly in different seasons of the year 2016 trapped by using methyl eugenol trap was shown in Fig. 3. In 2016, the highest mean numbers $(388.95 \pm 8.56$ FTD $)$ was recorded on 6th June and the lowest mean numbers (2.33 \pm 0.20 FTD) on 12th December (Fig. 3).

The positive and significant correlation $(\mathrm{Pr}=0.001)$ was observed between the mean number of FTD and minimum temperature and rainfall in 2011 (Table 1). This finding was corroborated with Hasyim et al. [34] who reported that rainfall and rainy days had positive and highly significant correlation with fruit flies caught per trap per day. The present study is similar result of the previous studies by Jalaluddin et al. [32] and Ingoley et al. [35]. The positive correlation was recorded between mean number of FTD and maximum temperature. Sunshine hour negatively with fly incidence which indicated that sunnier the day less was the fly activity in Table 1 . It might be like that during sunny days the flies prefer to congregate below the leaf surface or under the shade of vegetation. Similar trend was observed in 2016 (Table 2). The variable of minimum temperature was highest $(0.40)$ and (0.48) among four variables so that the population fluctuation of oriental fruit fly was largely depended on the minimum temperature in 2011 and 2016. Kannan et al. [36] reported that the minimum temperatures and oriental fruit fly population had positive relationship. Maximum temperature was found to be a positively correlated with fruit fly 


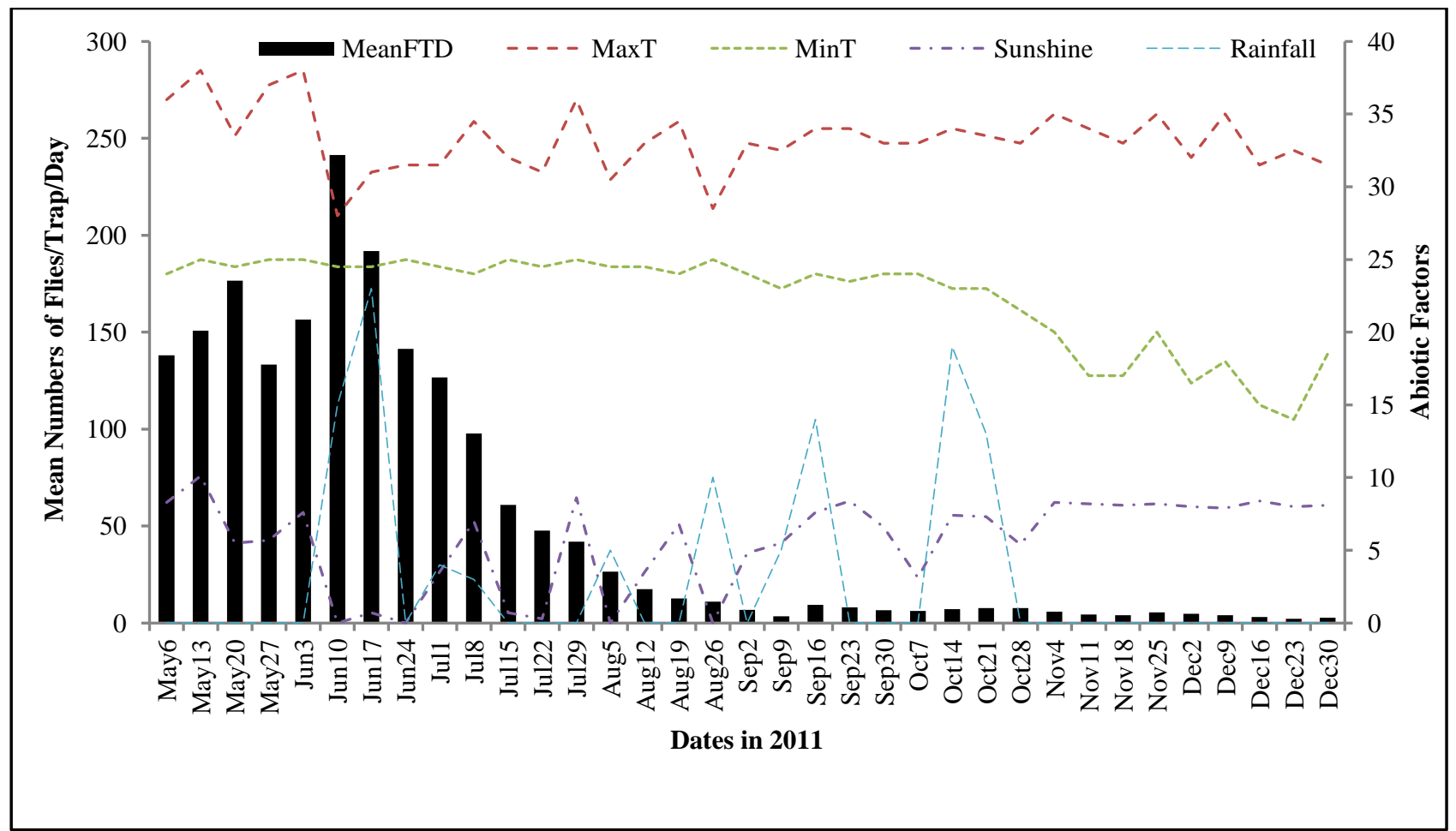

Fig. 2 Relationship between mean number of flies/trap/day and abiotic factors in 2011.

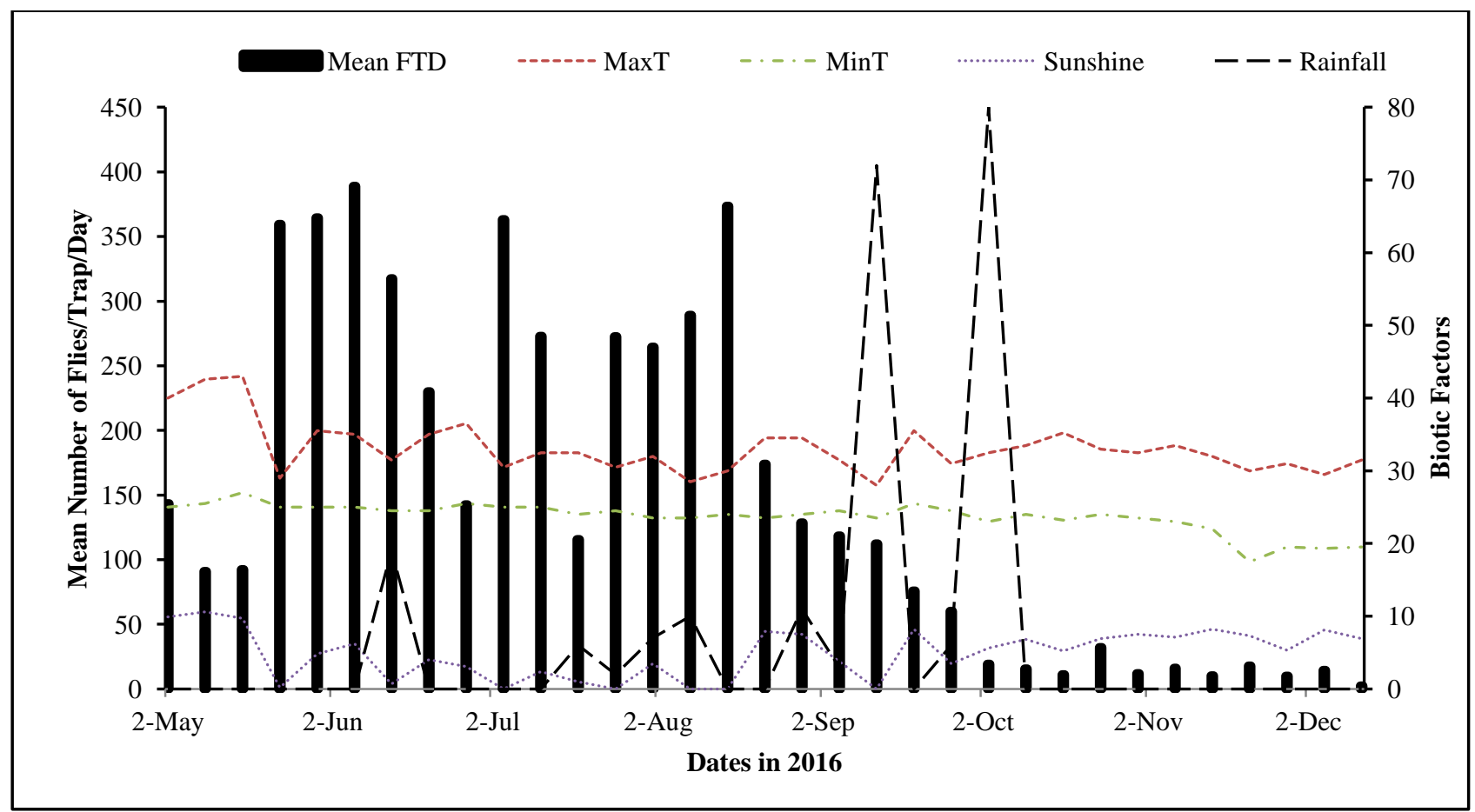

Fig. 3 Relationship between mean number of flies/trap/day and abiotic factors in 2016 . 
Table 1 Correlation coefficient $(r)$ between flies per trap per day and weather condition at Yezin during May, 2011 to December, 2011.

\begin{tabular}{|c|c|c|c|c|}
\hline Traits & Flies/trap/day & $\operatorname{Max} \mathrm{T}$ & Min $T$ & Rainfall \\
\hline Flies/trap/day & 1.00 & & & \\
\hline $\operatorname{Max} \mathrm{T}$ & 0.02 & 1.00 & & \\
\hline $\operatorname{Min} \mathrm{T}$ & $0.40 * *$ & 0.06 & 1.00 & \\
\hline Rainfall & $0.20 * *$ & $-0.36 * *$ & $0.25 * *$ & 1.00 \\
\hline Sunshine & $-0.27 * *$ & $0.71 * *$ & $-0.49 * *$ & $-0.31 * *$ \\
\hline
\end{tabular}

Table 2 Correlation coefficient $(r)$ between flies per trap per day and weather condition at Yezin during May, 2016 to December, 2016.

\begin{tabular}{|c|c|c|c|c|}
\hline Traits & Flies/trap/day & $\operatorname{Max} \mathrm{T}$ & $\operatorname{Min} \mathrm{T}$ & Rainfall \\
\hline Flies/trap/day & 1.00 & & & \\
\hline $\operatorname{Max} \mathrm{T}$ & 0.13 & 1.00 & & \\
\hline $\operatorname{Min} T$ & $0.48 * *$ & $0.49 * *$ & 1.00 & \\
\hline Rainfall & $0.11 * *$ & $-0.25 * *$ & $0.03 * *$ & 1.00 \\
\hline Sunshine & $-0.60 * *$ & $0.68 * *$ & $-0.12 * *$ & $-0.25 * *$ \\
\hline
\end{tabular}

** Significant at the $p<0.01$;

Flies/trap/day $=$ flies per trap per day, Max $\mathrm{T}=$ maximum temperature $\left({ }^{\circ} \mathrm{C}\right)$, Min $\mathrm{T}=$ minimum temperature $\left({ }^{\circ} \mathrm{C}\right)$, rainfall $(\mathrm{mm})$, sunshine (hour).

population in 2011 and 2016. It may be assumed that population density of fruit flies can be estimated based on the abiotic factors such as temperature and rainfall. The variable sunshine $(-0.27)$ and $(-0.60)$ were negatively and significantly correlated with the population if fruit flies in 2011 and 2016 (Table 1). This finding was similar result of Sarada et al [37] who recorded that fruit fly population of Bactrocera spp. had positive correlation with minimum temperature. Similar findings had been reported by Gupta et al. [29] who pointed out a positive correlation of Bactrocera dorsalis population with minimum temperature. Minimum temperature and population of guava fruit fly Bactrocera correcta had the same positive correlation [15].

All abiotic factors contribute significantly toward increasing or decreasing fruit flies trapped with the help of sex attractant. Lui et al. [31] reported that positive and highly significant correlation of Dacus zonatus incidence with minimum and maximum temperature. Hasyim et al. [34] also recorded that the number of fruit flies captured with cuelure baited traps positively correlated with temperature, humidity and rainfall. The influence of meteorological parameters on the incidence of melon fly was also claimed by Mahmood et al. [22]. In contrast, significant negative correlations were found between population fluctuations and sunshine hours, suggesting that cloudy days might favour increases in population size.

\section{Conclusions}

The result from this experiment it may be concluded that during high temperature and high rainfall periods (May-August) farmers and researchers should pay extra attention to formulate a sustainable management technique against the oriental fruit fly. To develop a sustainable management program of fruit flies farmers may apply fruit bagging, field sanitation, protein bait spray, male annihilation technique, sterile male release, augmentation of biological control agents and insecticides in the mango orchard.

\section{References}

[1] Aluja, M. 1994. "Bionomics and Management of Anastrepha." Annal. Rev. Entomol. 39: 155-78. 
[2] Ooi, P. C. C. 1991. "Integrated Pest Management in the Asia-Pacific Region." In Proceedings of the Conference on IPM in the Asia Pacific Region. Kualalampur, Malaysia.

[3] Alyokhin, A. V., Mille, C., Messing, R. H., and Duan, J. J. 2001. "Selection of Pupation Habitats by Oriental Fruit Fly Larvae in the Laboratory." J. Insect Behav. 14 (1): 57-67.

[4] Butani, D. K. 1979. Insects and Fruits. Delhi: Periodical Expert Book Agency.

[5] Kapoor, V. C., and Agarwal, M. L. 1982. "Fruit Flies and Their Increasing Host Plants in India." In Proceedings of the CEC/IOBC International Symposium Athens. Greece. 252.

[6] Kaplan, K. 2007. "Bactrocera dorsalis Complex Hendel." http://www. Ars.usda.gov/is/pr/2007/070601.htm.

[7] Drew, R. A. I., and Hancock, D. L. 1994. "The Bactrocera dorsalis Complex of Fruit Flies (Diptera: Tephritidae: Dacinae) in Asia." Bull Entomol Res. Suppl. 2: 84-8.

[8] Morris, H., and Waterhouse, D. F. 1998. "The Distribution and Importance of Arthropod Pests and Weeds of Agriculture in Myanmar." ACIAR (Australian Centre for International Agricultural Research) Monograph. (67): 73.

[9] Kapatos, E. T., and Fletcher, B. S. 1984. "The Phenology of the Olive Fly, Dacus oleae (Gmel.) (Diptera: Tephritidae) in Corfu. Z. Angew." Entomol 97: 360-70.

[10] Chen, P., and Ye, H. 2006. "Population Dynamics of Bactrocera dorsalis (Diptera: Tephritidae) along with Analysis on the Factors Influencing the Population in Ruili, Yunnan Province." Acta Ecologica Sinica 26: 2801-9.

[11] Shi, W., Kerdelhue, C., and Ye, H. 2005. "Population Genetic of The Oriental Fruit Fly, Bactrocera Dorsalis (Diptera: Tephritidae), in Yunnan (China) Based on Mitochondrial DNA Sequences." Env. Entomol 34: 977-83.

[12] Khan, M. A., Ashfaq, M., Akram, W., and Lee, J. 2005. "Management of Fruit Flies (Diptera: Tephritidae) of the Most Perishable Fruits." Entomol Res. 35 (2): 79-84.

[13] McQuate, G. T., Peck, S. L., Barr, P. G., and Sylva, C. D. 2005. "Comparative Evaluation of Spinosad and Phloxine B as Toxicants in Protein Baits for Suppression of Three Fruit Fly (Diptera: Tephritidae) Species." $J$. Econ. Entomol 98: 1170-8.

[14] Shelly, T. E., Pahio, E., and Edu, J. 2004. "Synergistic and Inhibitory Interactions between Methyl Eugenol and Cue Lure Influence Trap Catch of Male
Fruit Flies, Bactrocera dorsalis (Hendel) and $B$. cucurbitae (Diptera: Tephritidae)." Florida Entomologist 87 (4): 481-6.

[15] Hendrichs, J., Robinson, A. S., Carol, J. P., and Enkerlin, W. 2002. "Mediterranean Fruit Fly Area-Wide Sterile Insect Technique Programmes for Prevention, Suppression on Eradication: The Importance of Mating Behavior Studies.” Flo. Entomol 85: 1-13.

[16] CABI (CAB International). 2007. Crop Protection Compendium: Global Module [CD-Rom]. Wallingford: CABI.

[17] IAEA (International Atomic Energy Agency) 2005 Trapping Guidelines for Area Wide Fruit Fly Programmes. Vienna. 48pp.

[18] Gomez, K. A., and Gomez, A. A. 1984. Statistical Procedures for Agricultural Research. New York: John Wiley \& Sons.

[19] Shukla, R. P., and Prasad, V. G. 1985. "Population Fluctuation of the Oriental Fruit Fly, Dacus Dorsalis Hendel in Relation to Host and Abiotic Factors." Tropical Pest Management 31: 273-5.

[20] Agarwal, M. L., and Kumar, P. 1999. "Effect of Weather Perameters on Population Dynamics of Peach Fruit Fly, Bactrocera Zonata (Saunders)." J. Entomol 24 (1): 81-4.

[21] Mwatawala, M. W., Meyer, M. D., Makundi, R. H., and Maerere, A. P. 2006. "Biodiversity of Fruit Flies (Diptera: Tephritidae) in Orchards in Different Agro-ecological Zones of the Morogoro Region, Tanzania." Fruits 61 (5): 321-32.

[22] Mahmood, T., Hussain, S. I., Khokhar, K. M., and Hidayatullah, M. A. 2002. "Studies on Methyl Eugenol as a Sex Attractant for Fruit Fly, Dacus Zonatus (Saund) in Relation to Abiotic Factors in Peach Orchard." Asian J. Plant Science 4: 401-2.

[23] Amice, R., and Sales, F. 1979. Seasonal Abundance of Fruit Flies in New Caledonia. Management of Fruit Flies in the Pacific. ACIAR Proc. 76:134-139.

[24] Khan, M. A., Ashfaq, M., and Khaliq, A. 2003. "Role of Abiotic Factors in Population and Infestation Fluctuation of Fruit Flies in Guava Orchards of Sheikhupura District." Pak. Entomologist 25 (1): 89-93.

[25] Fletcher, B. S. 1989. "Life History Strategies of Tephritid Fruit Flies.” In: Robinson A. S. Hooper G (ads) Fruit Flies: Their Biology, Natural Enemies and Control (World Crop Pests Series). Amsterdam: Elsevier.

[26] Chen, P., and YE, H. 2007. "Population Dynamics of Bactrocera Dorsalis (Diptera: Tephritidae) and Analysis of Factors Influencing the Populations in Baoshanba, Yunnan Province." Entomol Science 10: 141-7.

[27] Mann, G. S. 1996. Seasonal Incidence and Build- 


\section{Relationship between Population Fluctuation of Oriental Fruit Fly Bactrocera dorsalis Hendel and Abiotic Factors in Yezin, Myanmar}

up of Bactrocera dorsalis Hendel on Mango in Punjab. J. Insect. Sci. 9(2): 129-32.

[28] Verghese, A., and Sudhadevi, K. 1998. Relation between Trap Catch of Bactrocera dorsalis Hendel and Abiotic Factors. In Proc. First National Symposium on Pest Management in Horticultural Crops. Bangalore. Pp. 15-8.

[29] Gupta, D., and Bhatia, R. 2000. "Population Fluctuations of Fruit Flies, Bactrocera Spp. in Submountainous Mango and Guava Orchards." $J$. Applied Horticulture 2: 47-9.

[30] Laskar, N., and Chatterjee, H. 2010. "The Effect of Meteorological Factors on the Population Dynamics of Melon Fly, Bactrocera Cucurbitae (Coq.) (Diptera: Tephritidae) in the Foot Hills of Himalaya." J. Appl. Sci. Environ Manage 14 (3): 53-8.

[31] Lui, Y. C., and Yeh, C. C. 1982. "Population Fluctuation of the Oriental Fruit Fly, Dacus dorsalis Hendel in Sterile Fly Release and Control Area." Chinese J. Entomol 2: 57-70.

[32] Jalaluddin, S. M., Natarajan, K., and Kathulla, S. S. 2001. "Population Fluctuation of the Guava Fruit Fly,
Bactrocera correcta (Bezzi) in Relation to Hosts and Abiotic Factors." J. Exp. Zool 4 (2): 323-7.

[33] Murthy, J. N. A., and Regupathy, A. 1992. "Seasonal Incidence of Moringa Fruit Fly, Gitona Spp.' South Indian Horticulture 40 (1): 43-8.

[34] Hasyim, A., Muryati, W. J., and Kogel, D. 2008. "Population Fluctuation of the Adult Males of the Fruit Fly, Bactrocera Tau Walker (Diptera: Tephritidae) in Passion Fruit Orchards in Relation to Abiotic Factors and Sanitation.” Indonesian J. Agri. Science 9 (1): 29-33.

[35] Ingoley, P., Hehta, P. K., and Verma, K. S. 2002. "Seasonal Occurrence of Fruit Fly, Bactrocera Cucurbitae Coq. on Cucumber in Midhills of Himachal Pradesh.” Himachal J. Agric. Res. 28 (1/2): 48-53.

[36] Kannan, M., and Venugopala, N. R. 2006. "Ecological Studies on Mango Fruit Fly, Bactrocera dorsalis Hendel." Ann. Plant Protection Sciences 14 (2): 340-2.

[37] Sarada, G., Mageswari, T. U., and Purushotham, K. 2001. "Seasonal Incidence and Population Fluctuation of Fruit Flies in Mango and Guava." Indian J. Entomol. 63: 272-6. 